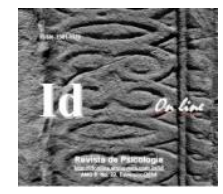

\title{
Percepção dos Portadores de Úlcera Venosa sobre a Assistência de Enfermagem na Atenção Primária
}

\author{
Francisca Patrícia Braga de Brito Farias ${ }^{1}$; Maria do Socorro Queiroga de Carvalho Passos ${ }^{2}$ \\ Pollyanna Nayara Belem Leite ${ }^{3}$ : Marianna Leite Barroso ${ }^{4}$
}

\begin{abstract}
Resumo: Na atenção primária a enfermagem é contemplada com uma dupla dimensão, gerencialista/assistencialista, o que resgata uma atuação ampliada no que diz respeito à execução de várias ações. É no contexto assistencialista das ações de enfermagem que se embasa esse estudo com maior ênfase para atenção primária à saúde do portador de Úlceras Venosas (UV), já que o cuidado e tratamento das feridas têm sido um campo de atuação dos enfermeiros. As Úlceras Venosas correspondem a uma síndrome em que ocorre destruição das estruturas cutâneas. Esta patologia causa significante impacto social devido ao longo tempo decorrido entre sua abertura e cicatrização e o elevado número de recidivas quando as feridas não recebem assistência adequada. Este estudo teve como objetivo analisar a percepção dos portadores de úlcera venosa diante da Assistência de Enfermagem na atenção primária. Trata-se de uma pesquisa do tipo exploratório, de caráter descritivo, de campo com abordagem qualitativa. Foi desenvolvida no domicílio de pacientes cadastrados nas Unidades Básicas de Saúde localizadas na zona urbana do Município de Iguatu - CE. A população foi composta pelos portadores de úlcera venosa e a amostra representada por sete colaboradores, obedecendo a critérios de inclusão e exclusão. Foi utilizada como instrumento para coleta de dados uma entrevista semiestruturada. Os dados foram coletados nos meses de novembro e dezembro de 2011. Para a análise qualitativa das informações obtidas por meio das questões norteadoras da pesquisa, foi utilizada a técnica de análise de conteúdo de Bardin (2011). Este trabalho foi norteado pelos aspectos éticos que envolvem pesquisas com seres humanos, de acordo com a resolução 196/96 que assegura o anonimato e a privacidade das informações, caracterizando o perfil dos portadores de úlceras venosas em sua maioria, 57\% com faixa etária superior a 60 anos de idade, $86 \%$ do sexo feminino, $43 \%$ com renda mensal de um salário mínimo e $57 \%$ possuem ensino fundamental incompleto comprovando assim o baixo nível de escolaridade dos entrevistados. Os principais resultados evidenciaram que na percepção dos portadores de úlcera venosa ocorre uma falta de compromisso dos profissionais de enfermagem que prestam assistência a eles na Unidade Básica de Saúde e no seu domicílio, resultando numa assistência precária. Os dados revelam que a uma carência de informações dos entrevistados sobre a sua patologia e quanto às ações fornecidas pela equipe de enfermagem no tratamento das suas lesões, que são precárias voltadas apenas para troca de curativo e medicação. Quanto às dificuldades encontradas pelos portadores de úlcera venosa durante o tratamento das lesões são, de um modo geral, aumento dos encargos financeiros e a falta de assistência. Por fim, diante dos resultados deste estudo, fica evidente a necessidade das contribuições da equipe de enfermagem na efetivação de uma assistência de qualidade que englobe todas as dimensões do ser e, consequentemente, sua qualidade de vida.
\end{abstract}

Palavras-chave: Úlcera Venosa; Assistência de Enfermagem; Atenção Primária.

\section{Perception of Patients with Venous Ulcer on Nurse Care in Primary}

\begin{abstract}
In the primary attention the nursing is contemplated with a Double dimension, managerial/assistentialist, that rescues an enlarged action respect to the execution of several actions. It's in the assistentialist context of the nursing's actions that follows this research with special attention to the health of the sick person of venous ulcer, because the care and treatment of the wounds have been a field of work of the nurses. The venous ulcers correspond to a syndrome where occurs the destruction of the cutaneous structures. This illness causes a significant social impact, because of the long time between its opening and the heal and the high number of recidives when the wounds don't receive the right care. This work had as objective to analyze
\end{abstract}

\footnotetext{
${ }^{1}$ Prof ${ }^{\text {a }}$. Esp. Graduada pela Universidade de Fortaleza - UNIFOR. Especialista em Unidade de Terapia Intensiva - UECE

${ }^{2}$ Acadêmica de Enfermagem da Universidade Regional do Cariri - URCA, Campus Avançado de Iguatu

${ }^{3}$ Enfermeira e Pós-graduada em Políticas Públicas em Saúde Coletiva pela URCA. E-mail: pollybelem@yahoo.com.br.

${ }^{4}$ Mestranda em Saúde pública pela Universidade Tecnológica Intercontinental - UTIC/PY. E-mail: mariannaleite_@hotmail.com
} 
the view of the people that suffer of venous ulcer in the case of the nursing primary attention. It's a kind of exploratory research in a descritive way, with a qualitative manner. It has been developed at the home of the selected patients at Basic Unit of Health, located in the urban zone of the country of Iguatu- Ceará. The population has been composed of the suffers of venous ulcer and the sample has been represented for seven contributes following by means of criteria inclusion and exclusion. It was used as an instrument of collection of data in a semi-structured interview. The data were collected during the months of November and December of 2011. For the qualitative analyzes of the informations, gotten by means of questions thought the research, it has been used the technique of analyzes of content of Bardin. This research follows the ethical aspects that involve researches with human being, according to the resolution 196/96 that assure the anonymity and the privacy of the informations. Characterizing the profile of the suffers of venous ulcer in mostly of the cases, $57 \%$ with age group above 60 years old, $86 \%$ of the feminine sex, $43 \%$ with a monthly income of the minimum wage, and $57 \%$ have only the elementary school, proving the low-level of school frequency of the interviewed. The main results showed that in the view of the suffers of venous ulcer occurs a lack of commitment of the nursing professionals who give them care at the nursing professionals who give them care at the Basic Unit of Health and at their home resulting in a bad care. The data shows that there is a lack of informations of the people about their pathology and about the actions supplied for the team of nursing in the treatment of their injuries, this treatment isn't well done It's made just with the change of dressing and medicine. In relation to the difficulties found for those who suffer of venous ulcer during the treatment of the injuries, they are general, increasing of the financial expenses and lack of care. At the end, from the results of this research, it's obvious the necessity of the contribution of the team of nursing in the effective care of quality that involve all the extent of the human being, and consequently, his quality of life.

Keywords: Venous Ulcer; Care of Nursing; Primary Attention.

\section{Introdução}

A Atenção Básica à Saúde é uma política do Sistema Único de Saúde (SUS) que compreende um conjunto de ações, individuais e coletivas, englobando promoção da saúde, prevenção de agravos, tratamento e reabilitação. É o primeiro nível da atenção (MACHADO e XAVIER, 2005).

Na década de 90 do século XX, o Ministério da Saúde implantou o Programa Saúde da Família (PSF) na intenção de reorganizar a assistência populacional no que diz respeito à atenção básica, englobando um complexo de ações a nível coletivo e/ou individual na tentativa de prevenir doenças e promover saúde sem, no entanto, excluir o tratamento, diagnóstico e a reabilitação dos pacientes. A atenção básica além de delimitar e desenvolver ações a toda uma população articula-se oferecendo referência, promoção e proteção à saúde (SILVA, 2005).

O PSF propõe uma nova dinâmica para a estruturação dos serviços de saúde, bem como para a sua relação com a comunidade e entre os diversos níveis e complexidade assistencial. Assume o compromisso de prestar assistência universal, integral, equânime, contínua, e acima de tudo resolutiva à população, na unidade de saúde e no domicílio, sempre de acordo com as suas reais necessidades. Além disso, deve identificar os fatores de risco a que a comunidade está exposta intervindo de forma apropriada (BRASIL, 2002). 
Dentro do PSF, a Enfermagem se constitui num instrumento de trabalho da saúde coletiva, subordinando-se às necessidades de saúde da população sobre sua responsabilidade a qual deve intervir sobre o processo saúde-doença do coletivo. Portanto é sem dificuldades que identificamos que a presença do profissional enfermeiro não se classifica apenas em atividades de supervisão, controle e coordenação de uma equipe. O PSF contempla a enfermagem com uma dupla dimensão, gerencialista/assistencialista, o que resgata uma atuação ampliada para a enfermagem no que diz respeito à execução de várias ações (BRASIL, 2004).

É no contexto assistencialista das ações de enfermagem que se embasa esse estudo com maior ênfase para atenção primária à saúde do portador de Úlceras Venosas (UV), já que o cuidado e tratamento das feridas têm sido um campo de atuação dos enfermeiros.

As Úlceras Venosas, também conhecidas como úlceras de estase, úlceras varicosas e úlceras flebopáticas, correspondem a uma síndrome em que ocorre destruição das estruturas cutâneas, como a epiderme, derme, podendo atingir os tecidos mais profundos. Normalmente se manifestam no terço inferior das pernas e iniciam de maneira espontânea ou traumática, em tamanho e profundidade variável, sendo únicas ou múltiplas, caracterizando-se pelas bordas irregulares, superficial, com presença de exsudato amarelado e raramente possuem tecido necrótico e exposições de tendões (MARTINS e SOUZA, 2007).

As Úlceras Venosas representam cerca de $70 \%$ a $90 \%$ dos casos de úlcera de perna, sendo comum na população idosa, com frequência superior a 4\% em idosos acima de 65 anos. Essa patologia causa significante impacto social devido ao longo tempo decorrido entre sua abertura e cicatrização e o elevado número de recidivas quando as feridas não são manejadas adequadamente (CARMO, CASTRO, RIOS e SARQUIS, 2007).

Cerca de $30 \%$ das UV cicatrizadas recorrem no primeiro ano e esse valor sobe para $78 \%$ no segundo ano, constituindo assim um dos problemas mais importantes na assistência a portadores que necessitam de tratamento prolongado e de cuidado integral, já que esta doença afeta o ser humano por completo (ABBADE e LASTÓRIA, 2006).

Considera-se que o tratamento da UV é complexo, de longa duração e que necessita de conhecimento específico, habilidade técnica, atuação interdisciplinar, articulação entre os níveis de complexidade de assistência e participação ativa do portador e seus familiares dentro de uma perspectiva holística (BORGES e GOMES, 2001).

Quando a assistência aos pacientes com UV é feita de forma inadequada, a lesão pode permanecer anos sem cicatrizar, acarretando um alto custo social e emocional. Em inúmeros casos, afasta o indivíduo do trabalho, agravando as condições socioeconômicas já precárias (FIGUEIREDO, 2000).

Id en lime Revista de Psicologia. Ano 8, No. 22, Fevereiro/2014 - ISSN 1981-1179. Edição eletrônica em http://idonline.emnuvens.com.br/id 
Uma significativa parcela dos pacientes portadores de UV não possui acesso e conhecimento sobre o tratamento adequado. Muitos pacientes são abordados por profissionais de saúde que utilizam técnicas incorretas, devido à inacessibilidade de técnicas e produtos de avançada tecnologia para o tratamento das lesões, tornando a referida patologia um grave problema de saúde pública. No entanto, é importante considerar que o tratamento deve ser dirigido não apenas às lesões, mas sim ao indivíduo como um todo.

A motivação pelo presente estudo advém da experiência vivenciada durante os estágios curriculares do Supervisionado I na Unidade de Saúde da Família, quando houve a oportunidade de observar os cuidados prestados a um portador de Úlcera Venosa, conhecendo a sua história, medos, dúvidas e esperança de cicatrização da ferida. É perceptível que nessas observações o fator psicológico do paciente deve ser levado em consideração, pois há uma influência maior no que diz respeito aos medos, ao preconceito, à autoestima e às emoções que podem causar. Além do ferimento físico, são capazes de deixar marcas indeléveis na alma.

Frente a estas considerações, surgiu a necessidade de conhecer a realidade assistencial, propondo as seguintes questões da pesquisa: Qual a percepção dos portadores de úlceras venosas quanto à Assistência de Enfermagem na atenção primária? Os cuidados oferecidos pela equipe de enfermagem têm tido uma resposta positiva no tratamento das Úlceras Venosas? Quais as dificuldades que os pacientes enfrentam durante o tratamento? Quais os sentimentos vivenciados pelo paciente em relação à presença das lesões?

Considerando que a assistência ao portador de UV é um processo complexo e dinâmico, conhecer a realidade poderá subsidiar a melhoria da qualidade de vida dos pacientes. Também ressaltamos que os resultados desta pesquisa poderão ajudar com o desenvolvimento de novas práticas educativas que subsidiem uma formação transformadora, não só a nível local, mas que, divulgados na academia, possam servir de referência para os discentes, docentes e pesquisadores, possibilitando desta forma a busca por novos conhecimentos acerca da temática.

O estudo teve como pontos principais a serem abordados, os seguintes objetivos: analisar a percepção dos portadores de úlcera venosa diante da Assistência de Enfermagem na atenção primária; averiguar as informações dos entrevistados sobre úlcera venosa; descrever as ações da equipe de enfermagem fornecidas aos portadores de úlceras venosas; verificar as possíveis dificuldades enfrentadas pelos portadores de úlceras venosas durante o tratamento; identificar as alterações no estilo de vida e os sentimentos vivenciados pelos pacientes relacionados com a presença e o tempo de existência das lesões. 


\section{Método}

Trata-se de uma pesquisa do tipo exploratório, de caráter descritivo, de campo com abordagem predominantemente qualitativa.

A pesquisa exploratória visa a proporcionar um maior conhecimento para o pesquisador acerca do assunto, a fim de que esse possa formular problemas mais precisos ou criar hipóteses que possam ser pesquisadas por estudos posteriores. Dessa forma, a pesquisa exploratória proporciona uma visão geral de um determinado fato e tem como objetivo proporcionar maior familiaridade com o problema (GIL, 2010).

A pesquisa de natureza descritiva é aquela que tem como foco essencial o desejo de conhecer uma realidade, ou seja, descrever fatos e fenômenos de uma determinada situação (TRIVIÑOS, 2010).

Contextualizando o texto acima, a pesquisa qualitativa busca trabalhar com o universo de significados, motivações, crenças, valores e atitudes, correspondentes a um espaço mais profundo das relações, dos processos e dos fenômenos que não podem ser reduzidos à operacionalização de variáveis. Este tipo de pesquisa valoriza a compreensão dos significados dos eventos, sem a necessidade de apoiar-se em informações estatísticas (MINAYO, 2010).

A presente pesquisa foi desenvolvida no domicílio dos portadores de úlcera venosa cadastrados nas Unidades Básicas de Saúde localizadas da zona urbana do Município de Iguatu. O Município consta com 25 Equipes de Saúde da Família, sendo 14 distribuídas na zona urbana que 11 estão localizadas na zona rural. A escolha da área urbana foi justificada em virtude da condicionalidade para o deslocamento, e acessibilidade aos domicílios, os quais são fatores que oferecem agilidade na coleta de informações.

A população desta pesquisa foi composta pelos pacientes cadastrados nas Unidades Básicas de Saúde, portadores de úlcera venosa que recebiam cuidados diretos da equipe de enfermagem. A mostra foi composta por sete (07) colaboradores. A seleção da amostra obedeceu a critérios de inclusão e exclusão.

Foram utilizados como critério de inclusão para a amostra portadores de úlceras venosas que estavam em tratamento na atenção primária, maiores de 18 anos, ambos os sexos, apresentavam capacidade de compreensão e de comunicação e os que aceitaram participar voluntariamente da pesquisa. Dentro do critério de exclusão portadores de úlceras venosas que não estavam em tratamento na atenção primária, menores de 18 anos, apresentavam incapacidade de compreensão e comunicação e os que não aceitaram participar voluntariamente da pesquisa. 
A população ou universo é um conjunto de todos os elementos que possuem determinadas características em comum. A amostra seria um subconjunto da população, através dela se permite estabelecer ou estimar as características da população (GIL, 2010).

Foi utilizado como instrumento para coleta de dados uma entrevista semi--estruturada (APÊNDICE A), baseada em um roteiro preliminar contendo questões fechadas que buscam traçar o perfil socioeconômico dos participantes e questões abertas que visam à análise qualitativa proposta nos objetivos da pesquisa.

Os dados foram coletados nos meses de novembro e dezembro de 2011. Para a efetivação da coleta de dados, realizou a abordagem dos portadores de úlceras venosas nos seus domicílios. Foi primeiramente apresentado o Termo de Consentimento Livre e Esclarecido, seguido da entrevista que foram gravadas em mídia digital no formato MP4 Player Titan 1GB, da marca Mirage, transcritas na íntegra. Após o final da pesquisa os arquivos de áudio foram excluídos.

A entrevista semi-estruturada é um dos principais meios de que dispõe o investigador para a realização da coleta de dados. Ao mesmo tempo em que valoriza a presença do pesquisador, permite que o informante alcance a liberdade, a espontaneidade e a legitimidade necessárias, fortalecendo a investigação (TRIVIÑOS, 2010).

A coleta de dados tem por finalidade reunir os dados pertinentes ao problema a ser investigado. A coleta e o registro dos dados pertinentes ao assunto tratado é a fase decisiva da pesquisa científica, a ser realizada com o máximo de rigor e empenho do pesquisador (PÁDUA, 2004).

Para a análise qualitativa das informações obtidas por meio das questões norteadoras da pesquisa, foi utilizada a técnica de análise de conteúdo como forma de organização dos dados. De modo geral, a sistematização dos dados segue três etapas: pré-análise, exploração do material e tratamento dos resultados obtidos e interpretação: 1. Pré-análise: organização do material (seleção dos documentos); 2. A exploração do material: os documentos são analisados profundamente, tomando como base suas hipóteses e referenciais teóricos. Neste momento se criam os temas de estudo e se pode fazer sua codificação, classificação e/ou categorização; 3. Tratamento dos resultados obtidos e interpretação: neste momento, a partir dos dados empíricos e informações coletadas, se estabelecem relações entre o objeto de análise e seu contexto mais amplo, chegando, até mesmo, a reflexões que estabeleçam novos paradigmas nas estruturas e relações estudadas (BARDIN, 2011).

Para a realização desta pesquisa foram levados em consideração os aspectos éticos contidos na Resolução 196/96 do Conselho Nacional de Saúde (CNS), que dispõe sobre diretrizes e regulamentos para realização de pesquisas que envolvem seres humanos (BRASIL, 1996).

O presente estudo foi submetido à análise do Comitê de Ética em Pesquisa da Universidade Regional do Cariri - URCA-CE, aprovado pelo parecer Nº7/2011. 
Após a aprovação foi enviado para a Secretaria Municipal de Saúde um pedido de autorização para realização da pesquisa (APÊNDICE B); em seguida os portadores de úlcera venosa que aceitaram participar do estudo assinaram o Termo de Consentimento Livre e Esclarecido (TCLE) (APÊNDICE C) em duas vias, contendo todas as informações acerca da pesquisa ficando uma via com o pesquisador e outra com o entrevistado.

Como procedimento ético, todos os participantes receberam explicações detalhadas sobre as finalidades e objetivos da pesquisa, sendo garantido o anonimato, a privacidade e a desistência em qualquer etapa de desenvolvimento da mesma, sem nenhum prejuízo ao sujeito. A partir daí, os entrevistados, voluntariamente, aceitaram em participar do referido estudo.

\section{Análise e Discussão dos Dados}

A análise dos dados foi realizada de acordo com os objetivos propostos neste estudo e organizada em etapas distintas. Na primeira etapa os participantes do estudo encontram-se caracterizados de acordo com os seus dados socioeconômicos. Na segunda etapa os dados qualitativos referentes às questões temáticas do estudo foram analisados seguindo os pressupostos da análise de conteúdo (BARDIN, 2011).

A amostra foi composta pelos portadores de úlcera venosa cadastrados nas UBSs de acordo com os critérios de inclusão e exclusão sendo traduzida com o número (n) de colaboradores ( $\mathrm{n}=7$ ).

$\mathrm{Na}$ apresentação dos dados socioeconômicos dos portadores de úlceras venosas, verifica-se na faixa etária da amostra, 43\% tinham idade entre 44 a 59 anos e 57\% eram maiores de 60 anos de idade.

Dentre esses resultados referentes à faixa etária observou-se que a amostra foi predominantemente constituída por pessoas maiores de 60 anos, pois é característica das úlceras venosas acometer em maior proporção os idosos, os quais tendem a serem marcados pelo maior número de condições crônicas degenerativas.

Em relação à distribuição dos colaboradores segundo o sexo, pode-se observar que $14 \%$ dos participantes são do sexo masculino e $86 \%$ do sexo feminino. Constata-se uma predominância de úlcera venosa na população feminina. Isso ocorre, pois no sexo feminino existem alguns fatores que contribuem e predispõe ao aparecimento de úlcera venosa.

Quanto à etnia, verificou-se que $43 \%$ da amostra apresentam raça de cor branca, $43 \%$ de cor mestiça e apenas $14 \%$ raça de cor negra. Desta forma observa-se uma menor porcentagem dos participantes de cor negra.

Id en line Revista de Psicologia. Ano 8, No. 22, Fevereiro/2014 - ISSN 1981-1179. Edição eletrônica em http://idonline.emnuvens.com.br/id 
Os dados referentes à distribuição dos participantes da pesquisa quanto ao estado civil, constaram que $43 \%$ são casados, $14 \%$ divorciados, $14 \%$ relacionamento não oficializado e $29 \%$ encontram-se viúvas.

Diante destes dados pode-se perceber que uma parcela significativa dos entrevistados não possui um companheiro para ajudar no enfrentamento do problema, visto que $14 \%$ são divorciados e 29\% são viúvas, surgindo daí a necessidade de um cuidador para o acompanhamento das suas necessidades diárias voltadas para o tratamento.

Quanto à renda familiar da amostra estudada, 28,5\% relataram possuir renda mensal menor que um salário mínimo, $43 \%$ afirmam receber um salário mínimo e 28,5\% mais de um salário mínimo. Ressalta-se que a maioria dos portadores de úlceras venosas é de baixa renda.

Sabe-se que o fator econômico é de grande valia e sem dúvida um importante indicador social, pois é através da renda que as pessoas conseguem comer, vestir, investir na sua própria educação e de seus filhos, garantir recursos para saúde, comprar remédios e fazer tratamentos que não são disponibilizados pelo SUS.

No tocante ao grau de escolaridade a tabela 1 mostra que $29 \%$ são analfabetos, $57 \%$ possuem o ensino fundamental incompleto e $14 \%$ o ensino médio incompleto. Os dados comprovam o baixo nível de escolaridade dos entrevistados, o que compromete o tratamento das lesões, uma vez que a carência de instruções prejudica na compreensão das orientações sobre os cuidados com as úlceras venosas.

Apesar da literatura não evidenciar a relação entre o grau de escolaridade e a incidência das úlceras venosa, sabe-se que essas informações são fundamentais para a recuperação e o tratamento das lesões.

Para a mente receber, recordar, analisar e aplicar as novas informações, precisa existir uma certa quantidade de capacidade intelectual, sendo que em casos especiais, como o analfabetismo, é necessário realizar adaptações, durante a implementação do ensino sobre saúde (TIMBY, 2001).

No tocante à situação profissional, verifica-se que $43 \%$ dos participantes encontram-se em situação laboral ativa, enquanto $57 \%$ são aposentados, ou seja, em situação laboral não ativa. Observou-se que a maioria dos colaboradores são aposentados por idade.

Conhecer e entender o cotidiano dos portadores de úlceras venosas gera uma reflexão sobre a realidade em que estão inseridos, pois a ocupação profissional, a idade, a renda familiar e o grau de escolaridade estão interligados, sendo fatores que interferem na qualidade de vida e no estado biopsicossocial.

Ao término da análise e discussões das características socioeconômicas, será apresentada a análise das questões que norteiam a temática em estudo. 
A análise foi organizada em sete categorias: informações dos entrevistados sobre úlceras venosas; percepção dos portadores de úlceras venosas acerca da assistência prestada pela equipe de enfermagem na Atenção primária; ações da equipe de enfermagem fornecida aos portadores de úlceras venosas; influência da assistência de enfermagem nos cuidados com a lesão; dificuldades vivenciadas durante o tratamento das lesões; sentimentos dos portadores de úlceras venosas relacionados com a presença e tempo de existência das lesões; alterações no estilo de vida dos portadores de úlcera venosa.

Ao averiguar as informações dos portadores de úlcera venosa sobre sua patologia. De acordo com as respostas dos entrevistados, observa-se uma carência de informações expressa nos relatos abaixo:

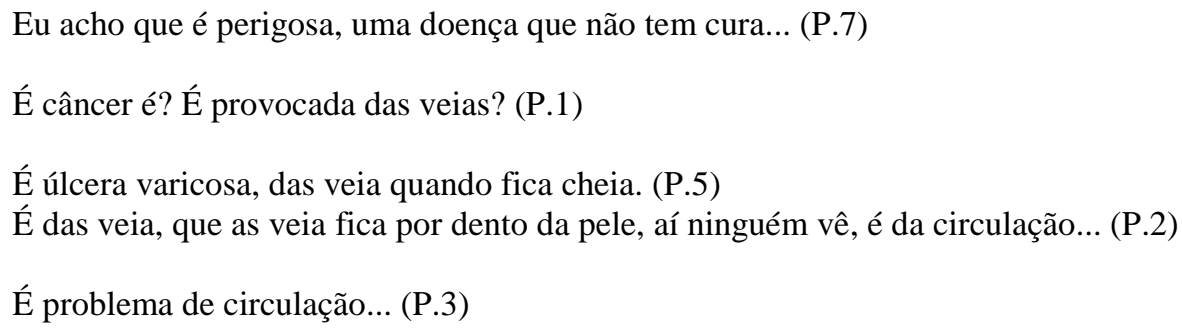

Nos depoimentos acima fica evidenciada a falta de conhecimento dos entrevistados sobre a sua patologia, o que muitas vezes está relacionada com o baixo nível de escolaridade que foi apresentado anteriormente nos dados socioeconômicos. Deste modo torna-se necessário que os portadores conheçam sua doença para saber o que esperar de cada situação, colaborando, dessa forma, com sua própria recuperação.

A carência de informações da população sobre sua doença está ligada a vários fatores tais como a inexistência de um programa educacional efetivo que instrui os indivíduos, a superlotação em centros de saúde que impede o profissional dispor de seu tempo para explicar ao paciente o que significa sua doença e a negligência dos pacientes em obter tais informações porque muitas vezes o médico já está cuidando dele (OLIVEIRA, 2004).

A variável escolaridade correlaciona-se positivamente com a qualidade de vida, sugerindo que os pacientes com mais anos de estudo podem possuir recursos intelectuais capazes entender melhor sua patologia, gerando uma melhor adaptação com as consequências da doença (MARTINS e CESARINO, 2005).

Ao analisar a percepção dos portadores de úlcera venosa deste estudo, sobre a assistência de enfermagem que eles recebem na Unidade Básica de Saúde e no seu domicílio, fica evidente nos depoimentos a seguir a falta de compromisso dos profissionais que resulta em uma assistência precária conforme fica nítido nas seguintes falas: 
Pra mim é fraca. O pessoal do posto nunca vieram aqui, vem a visita do mês só, a agente de saúde mandava eu assinar, aí pronto... A enfermeira nunca vei aqui, ela ficou de arrumar essa pomada colagenase pra mim, ainda não recebi. (P.1)

Antes vinha uma moça do posto que dava assistência a mim, muiezinha ela era muito ocupada aí ela não tinha tempo de vim, ela quem atende o povo todim, ela vinha todo dia de manhã... (P.4)

...Agora do posto eu só recebo meu remédio de pressão, ai um tempo desse eu fui consultar da minha ferida e a doutora passou foi um monte de remédio. (P.2)

Elas diz, isso ai é coisa normal não precisa se preocupar...Eu ia lá no postim quando precisava, nunca vieram na minha casa não... (P.6)

Ao analisarmos esses recortes de depoimentos, podemos notar que a enfermagem não está prestando uma assistência de qualidade, não conseguindo reproduzir uma assistência acessível, integral e resolutiva, os quais são parte integrante dos direitos sociais dos usuários da Atenção Primária.

A assistência ao paciente deve ser diária e, ao se estabelecerem metas para o cuidado, deve-se compartilhar com o paciente e seus familiares para que com a equipe decidam as melhores diretrizes a serem tomadas. Entretanto, essa participação exige do enfermeiro boa habilidade de comunicação para identificar e responder às necessidades individuais dos pacientes (CHAPLIN, 2004).

Considerando as percepções dos participantes, ressalta-se a necessidade do estreitamento da relação entre profissional e usuários, em especial a equipe de enfermagem, a qual tem como atribuição a prestação direta do cuidado aos portadores de lesões.

De acordo com as respostas dos entrevistados, as ações fornecidas pela equipe de enfermagem referente ao tratamento das suas lesões são precárias, as quais estão voltadas apenas para troca de curativo e medicação. Podemos observar nos seguintes relatos:

A técnica fazia o curativo e dizia pra eu não comer peixe, nada carregado, nem galinha caipira, nada. (P.4)

...Antes vinha uma pessoa do postim fazer os curativo, ela vinha todo dia mas não vem mais. (P.2)

...Ela passava o remédio só pra fora e fazia o curativo, não fazia orientação nenhuma. Só quem me orientou foi doutor Nogueira. (P.6)

Através das falas dos entrevistados, é possível observar que a enfermagem apresenta pouca participação nas ações referente ao tratamento dos portadores de úlcera venosa, realizando apenas troca de curativos, sem fazer orientações, o que pode interferir negativamente no processo de cicatrização, contribuindo para a manutenção da cronicidade da lesão. 
A literatura sustenta que a troca de curativo tem se constituído a principal forma de assistência disponível. A realização dessa atividade, na maioria das vezes, é delegada ao técnico/auxiliar de enfermagem, o que denota ausência de interdisciplinaridade e falta de avaliação integral do paciente. ${ }^{20}$

Dessa maneira o enfermeiro não pode ausentar-se, pois ele é de fundamental importância em todo o processo de cicatrização. Cabe a este profissional fazer a avaliação inicial, orientação, escolha dos produtos, troca de curativos, como também a capacitação dos técnicos de enfermagem.

Quando os portadores de úlcera venosa foram questionados sobre a influência dos cuidados oferecidos pela equipe de enfermagem, relacionados com a melhora das lesões, relataram que antes melhorava com os cuidados restritos apenas ao curativo, mas infelizmente não há continuidade, como podemos verificar nas falas a seguir:

Quando a moça do postim fazia melhorava... Agora eu tou melhor e minha menina aprendeu a fazer o curativo, ela faz do mesmo jeitim... (P.2)

Melhorava quando o doutor passava os remédio, mais agora ele só atende particular. (P.5)

...O doutor me operou, as vez eu comprava uma pomada e um comprimido aí miorava mais. (P.6)

Via melhora graças a Deus, mais não fico boa de tudo. (P.4)

Com base nos relatos observa-se a necessidade de uma assistência de enfermagem que contemple não apenas o cuidado com a pele, a realização de curativos e administração medicamentosa, mas também que possua um olhar mais humano, sensível e integral, de forma a propiciar melhora significativa na qualidade de vida do portador de úlcera venosa.

Na perspectiva do atendimento à saúde, é essencial agregar a eficiência técnica e científica ao desenvolvimento de ações que favoreçam a melhoria do atendimento à saúde. Nesse contexto, a equipe de enfermagem deve se conscientizar e se preparar para fazer a diferença no cuidado ao portador da ferida. $\mathrm{O}$ atendimento humanizado exige do profissional a disponibilidade para orientar, sanar dúvidas, proporcionando tranquilidade e segurança (BEDIN, RIBEIRO e BARRETO, 2004).

Os depoimentos a seguir expressam as principais dificuldades encontradas pelos portadores de úlcera venosa durante o tratamento das lesões, as quais estão relacionadas de um modo geral com o aumento dos encargos financeiros e a falta de assistência.

$\mathrm{Ah}$ ! Eu encontro. Porque ainda não encontrei um remédio para sarar rápido... O remédio é caro a Colagenase é 54 reais... (P.1)

A enfermeira nem vem olhar, não vem fazer meu curativo, eu fui quem comprei tudo, o soro, comprei a gaze, as vezes eu peço, mais elas diz que não tá esterilizado...(P.7) 
Se eu pudesse dobra essa perna fazia meu curativo, más quem faz é minha fia. (P.4)

...Fui uma consulta no posto a doutora disse que não tinha remédio pra isso. Eu nunca encontrei tratamento... (P.6)

Eu tenho que fazer um exame, só que não consegui. Eu moro sozinha, eu tenho raiva que a casa é muito grande pra mim, meus filhos mora tudo em São Paulo. Eu passo a tarde todinha com pé levantado. (P.3)

De acordo com os relatos é possível perceber que a existência de uma úlcera venosa causa dificuldades no cotidiano do portador, tais como falta de recursos financeiros para comprar produtos que não são disponíveis na rede pública, os quais podem gerar um ônus considerável na renda familiar dos usuários, pois como já vimos anteriormente, a maioria dos entrevistados deste estudo vive com uma baixa renda familiar.

As úlceras venosas representam um importante problema de saúde quer por sua prevalência, quer pelos custos econômicos e sociais decorrentes do tratamento, incapacidade e da dependência a elas associadas (TUYAMA, 2004).

Também é percebível que viver com a condição de ter uma ferida leva a necessidade de uma assistência qualificada para facilitar o tratamento e todos os aspectos que envolvem este problema. Uma lesão influencia de forma significativa no modo de ver e sentir a vida.

Portanto é imprescindível melhorar a qualidade de vida dos portadores de úlcera venosa, sendo fundamental amparo e estímulo para superação das dificuldades, quer seja de lazer, fortalecimento físico, psíquico ou emocional (DIAS e SILVA, 2006).

Ao identificar os sentimentos dos portadores de úlcera venosa, são notórias as frustrações vivenciadas por eles ao longo dos anos, as quais foram demonstradas por baixa autoestima, dor, alteração da imagem corporal, medo da amputação do membro, tristeza e revolta. Conforme os relatos clarificam:

Vai fazer 30 anos... Horrível... tinha dia deu num fazer nada, esperava pelos outro, porque dói mesmo. (P.1)

Tá com 19 anos que tenho essa ferida... Sinto vergonha do povo olhar, porque as perna tudo ferida, é difícil eu sair... (P.6)

Quase 10 anos... No começo sentia muita dor e não andava de jeito nenhum, eu tinha muito medo do doutor corta minha perna eu não dormia de noite, passava a noite todinha latejando... Agora eu já me acustumei com a dor. (P.3)

Tem 21 anos... Senti muito medo quando a veia estorou... (P.5)

Faz quais 6 anos...Tinha dia que eu chorava tanto só faltava ficar doida, só sentada. (P.4) 
Como é percebível nas falas dos colaboradores do estudo, a maioria é portadora das úlceras venosas há muito tempo, as quais ao longo dos anos causam sentimentos desagradáveis devido à dor, à vontade de chorar, ao medo da amputação, à tristeza, à vergonha da imagem corporal alterada e à impossibilidade de desempenhar as atividades de costumes.

Para muitos pacientes as úlceras venosas significam autoestima baixa, isolamento social e aspecto emocional negativo por desencadear constrangimento, tristeza, raiva e dor (BORGES e GOMES, 2001).

O fato de a úlcera venosa perdurar por vários anos acaba colocando o portador numa situação de apatia, desmotivação, comodismo. Essa rotina diária faz com que ele se acomode e perca a sua capacidade de acreditar na possibilidade de cura, consequentemente levando à redução da autoestima.

Em meio a tanto sofrimento, muitas vezes, o portador de ferida não se rende perante a desfiguração de seu corpo, ele luta com determinação, visando um dia superar todas as dificuldades que a ferida impôs por muitos anos em sua vida, mesmo diante de possíveis marcas que vão além de alterações de pele que atingem o seu individual (VIANA, SILVA, LUZIAL e GUEDES, 2007).

Quanto as alterações no estilo de vida fica evidente através dos relatos dos entrevistados que as úlceras venosas alteram seu estilo de vida causando muitas vezes abandono de trabalho, mobilidade física prejudicada, dificuldades para realizar suas atividades diárias, vergonha de sair de casa e também gera a preocupação em buscar estratégias para esconder a ferida.

Doía muito, não dava pra trabalhar, eu trabalhava na prefeitura no carro do lixo, aí parei quando estourou... (P.6)

Ah é horrível você não poder ir a uma praia, você não pode vestir um short pra sair... Nem para a igreja eu vou, num vou uma festa, num vou pra canto nenhum, as vez quando eu tou melhor eu enfrento... (P.1)

...Só vivo com as pernas trepada em cima do travessero... eu não varro casa, quem varre é minha menina. Olhe eu tinha o costume de varrer a casa quatro a cinco vez no dia. Nem sento na calçada, fico só dentro de casa. Eu tenho fé em Deus que eu fico boa. (P.4)

Eu dexei de sair, porque com essa perna enrolada, aí o povo fica vixe o que foi na tua perna, aí fica aquela comédia todinha, aí as vez eu enrolava e vistia uma calça comprida... (P.7)

Os entrevistados relatam que a úlcera venosa impõe a sua vida uma nova rotina, fazendo dele um indivíduo mais dependente e que em função desta dependência é afastado das suas atividades cotidianas, levando-o ao isolamento. Assim eles expressam como principais alterações no seu estilo de vida a descontinuidade de suas atividades diárias como trabalhar, passear, realizar atividades domésticas e ir à igreja. Estas alterações causam um impacto direto em seu meio social, resultando em modificações significativas na sua condição de vida, fazendo com que se sinta inferiorizado, limitado. 
$\mathrm{O}$ fato de as úlceras venosas exigirem terapêuticas prolongadas, muitas vezes leva a necessidade dos seus portadores se afastarem do trabalho o que interfere substancialmente em sua qualidade de vida (OLIVEIRA, LIMA e ARAÚJO, 2008).

Vale ressaltar que a condição de existência de uma ferida interfere em todo um contexto de vida, e que é de suma importância a disponibilidade de um cuidador, seja membro ou não da família, de modo que possa fornecer carinho e suporte para as suas atividades diárias, retirando o portador do quadro de solidão e de exclusão social, pois o cuidador além de prestar assistência deve programar atividades sociais que estejam dentro da condição do portador, restaurando-lhe o sentimento de ser útil (SILVA et al, 2008).

Percebe-se, então, que os autores supracitados corroboram com os achados da pesquisa, justificando que a condição de ser um portador de ferida leva ao afastamento das suas atividades laborais e altera o seu estilo de vida, comprometendo a sua satisfação com a vida e sua relação com o meio em que está inserido, demonstrando que o portador precisa conhecer bem os aspectos que envolvem este processo patológico, suas limitações e suas potencialidades, para que possa aceitar sua condição e adaptar-se a uma nova forma de viver.

\section{Considerações Finais}

A realização desta pesquisa permitiu que os objetivos fossem alcançados através dos relatos, ficando evidente a percepção dos portadores de úlcera venosa diante da Assistência de Enfermagem na atenção primária, o perfil socioeconômico da população estudada, as informações dos entrevistados sobre sua patologia, as ações da equipe de enfermagem, as dificuldades encontradas durante o tratamento, as alterações no estilo de vida e os sentimentos vivenciados pelos pacientes relacionados com a presença e o tempo de existência das lesões.

Este estudo caracterizou o perfil dos portadores de úlceras venosas em sua maioria, $57 \%$ com faixa etária superior a 60 anos de idade, $86 \%$ do sexo feminino, $43 \%$ relataram possuir renda mensal de um salário mínimo e no tocante ao grau de escolaridade $57 \%$ possuem o ensino fundamental incompleto comprovando assim o baixo nível de escolaridade dos entrevistados.

$\mathrm{Na}$ percepção dos portadores de úlcera venosa, ocorre uma falta de compromisso dos profissionais de enfermagem que prestam assistência a eles na Unidade Básica de Saúde e no seu domicílio, resultando numa assistência precária.

Os resultados apontam que há uma carência de informações dos entrevistados sobre a sua patologia. Quanto às ações fornecidas pela equipe de enfermagem no tratamento das suas lesões, estas são precárias voltadas apenas para troca de curativo e medicação. As principais dificuldades 
encontradas pelos portadores de úlcera venosa durante o tratamento das lesões são, de um modo geral, aumento dos encargos financeiros e a falta de assistência.

Também foi imprescindível identificar os sentimentos vivenciados pelos portadores de úlcera venosa ao longo dos anos os quais foram demonstradas por baixa autoestima, dor, alteração da imagem corporal, medo da amputação do membro, tristeza e revolta. Segundo os entrevistados, as úlceras venosas alteram seu estilo de vida causando muitas vezes abandono de trabalho, mobilidade física prejudicada, dificuldades para realizar suas atividades diárias e vergonha de sair de casa.

Assim, diante dos resultados deste estudo, fica evidente a importância que deve ser dada pelos profissionais de saúde aos diferentes aspectos que estão envolvidos no processo saúde-doençacuidado, a considerar os aspectos emocionais, psicológicos, econômicos e sociais. Sendo, portanto, relevante que a equipe de enfermagem possa contribuir com a efetivação de uma assistência de qualidade que englobe todas as dimensões do ser, pois cuidar da úlcera venosa é tão importante quanto o cuidar da vida.

Deste modo, este estudo colabora no cuidado do portador de úlcera venosa, possibilitando a criação de um plano de intervenção mais adequado para cuidar desse indivíduo, melhorando a assistência prestada e, consequentemente, sua qualidade de vida.

Por fim, esta pesquisa foi de suma importância ao permitir o enriquecimento como ser humano, aprendendo a compreender o paciente como um ser que possui angústia, medos e dúvidas, tendo em mente que a Assistência de Enfermagem é fundamental para proporcionar um bem estar biopsíquico e social para os portadores de Úlceras Venosas.

\section{Referências}

ABBADE, L.P.F.; LASTÓRIA, S. Abordagem de Pacientes com Úlceras de perna de etiologia Venosa. Anais Brasileiro de Dermatologia. v.81, n.6, 2006.

BARDIN, L. Análise de Conteúdo. São Paulo: Edições 70, 2011.

BEDIN, E.; RIBEIRO, L.B.M.; BARRETO, R.A.S. Humanização da assistência de enfermagem.

Revista Eletrônica de Enfermagem. v.5, n.3 p.400-4009, 2004

BORGES, E.L.; GOMES, F.S.L. Coberturas. In: BORGES E.L.; SAAR, S.C.; LIMA, V.L.A.N.;

GOMES, F.S.L.; MAGALHÃES. M.B.B. Feridas: como tratar. Belo Horizonte: Coopmed, 2001. 
BORGES, E.L.; GOMES, F.S.L. Coberturas. In: BORGES E.L.; SAAR, S.C.; LIMA, V.L.A.N.; GOMES, F.S.L.; MAGALHÃES. M.B.B. Feridas: como tratar. Belo Horizonte: Coopmed, 2001.

BRASIL. Ministério da Saúde. Conselho Nacional de Saúde, Resolução 196, de 10 de outubro de 1996 - Diretrizes e Normas Regulamentadoras de Pesquisas envolvendo seres humanos. Brasília, 1996.

BRASIL. Ministério da Saúde. Programa Saúde da Família. Manual de Condutas Médicas. Brasília, 2002.

. Ministério da Saúde. Avaliação Normativa do Programa de Saúde da Família no Brasil. Brasília: DF, 2004.

CARMO, S.S.; CASTRO, C.D.; RIOS, V.S.; SARQUIS, M.G. Atualidade na Assistência de Enfermagem a portadores de Úlceras Venosas. Revista Eletrônica de Enfermagem. v.9, n.2, p.50617, 2007.

CHAPLIN, J. Cuidados paliativos em feridas. Revista Nursing, v. 19, n. 1 p. 39-42; set/2004. Disponível: www.bireme.br.

DIAS, A.L.P.; SILVA, L. Perfil do portador de lesão crônica de pele: fundamentos da autopercepção de vida. Esc. Anna Nery.2006. Disponível: http//portalbvsenf.eerp/scielo.

FIGUEIREDO, M. Úlcera venosa. Revista Virtual de Medicina. v.1, n.9, ano 3, jan/fev/mar, 2000.

GIL, A. C. Como elaborar um projeto de pesquisa. 5. ed. São Paulo: Atlas, 2010.

MACHADO, K.; XAVIER. J. Atenção básica: equipes e unidades de saúde mais perto do cidadão. In: RADIS comunicação em saúde. n. 34. Rio de Janeiro. Jun., 2005.

MARTINS, D.A.; SOUZA, A.M. O Perfil dos clientes portadores de úlceras varicosas cadastradas em programa de Saúde pública. Revista Cogitare Enferm. v.1, n.1, p.353-7, Jul/Set, 2007. 
MARTINS, L.M.; CESARINO, C.B. Qualidade de vida de pessoas com doença crônica. Revista Latino Americana de Enfermagem, Ribeirão Preto. V.13, n.5; p.670-676. 2005.

MINAYO, M.C.S. O desafio do conhecimento: pesquisa qualitativa em saúde. 12 ed. São Paulo: Hucitec, 2010.

OLIVEIRA, B.G.B.; LIMA, F.F.L.; ARAÚJO, J.O. Ambulatório de reparo de feridas: perfil da clientela com feridas crônicas. Revista Nursing, v. 17, n. 2 2008. Disponível: http//WWW.scielo.com>.

OLIVEIRA, V.Z.; GOMES, W.B.. Comunicação médico-paciente e adesão ao tratamento em adolescentes portadores de doenças orgânicas crônicas. Estud. psicol. (Natal), Natal, v. 9, n. 3, 2004.

PÁDUA, E.M.M. Metodologia da pesquisa: abordagem teórico-prática. 10 ed. Campinas: Papirus, 2004.

PARANHOS, W.Y. Úlcera de pressão. In: JORGE, S.A.; DANTAS, S.R.P.E. Abordagem multiprofissional do tratamento de feridas. São Paulo: Atheneu, 2003.

SILVA, J.J.C. Saúde no Brasil: evolução histórica, SUS e desafios futuros. Dissertação de mestrado. Universidade Federal de Santa Catarina, 2005.

SILVA, R.C.L.; MEIRELES, I.B.; C.R.L.; PORTO, I.S.; LIMA, I.C.; SANTOS, J.D.; MARIS, R.P.; RIBEIRO, T.M.G.Sistematização da assistência enfermagem. Cap. 6. In: SILVA, R.C.L.; FIGUEIREDO, N.M.A.; MEIRELES, I.B. Fundamentos e atualizações em enfermagem, 2008.

TIMBY, Bárbara K. Conceitos e habilidades fundamentais no atendimento de enfermagem. Trad. Regina Garcez. $6^{\text {a }}$ ed. Porto Alegre: Artmed, 2001.

TRIVIÑOS, A.N.S. Introdução à pesquisa em ciências sociais: a pesquisa qualitativa em educação. 1 ed. 19 reimpr. São Paulo: Atlas, 2010. 
TUYAMA, L.Y. et al. Feridas crônica de membros inferiores: proposta de sistematização de enfermagem a nível ambulatorial. Revista Nursing, v. 74, n. 7, ago. 2004.

VIANA, A.D.; SILVA, R.C.L.; LUZIAL, N.; GUEDES, D. Feridas. Cap. 18. In: SILVA, R. C. L.; FIGUEIREDO, N.M.A.; MEIRELES, I.B. Fundamentos e atualizações em enfermagem. p. 363$385,2007$.

\section{Como citar este artigo (Formato ISO):}

FARIAS, F.P.B.B.; PASSOS, M.S.Q.C.; LEITE, P.N.B.; BARROSO, M.L. Percepção dos portadores de úlcera venosa sobre a assistência de enfermagem na Atenção Primária. Id on Line Revista de Psicologia, Fevereiro de 2014, vol.8, n.22, p. 105-122. ISSN 1981-1189.

Recebido: 20/12/2013

Aceito: 04/02/2014 